\title{
BIPOLAR AFFECTIVE DISORDER AND SUBSTANCE USE: THE DUAL DIAGNOSIS IN TREATMENT SEEKING PATIENTS
}

\author{
Ab Majid Gania, Mushtaq A. Margoob.
}

1. Consultant, Department of Psychiatry, SKIMS Medical College \& hospital Bemina, Srinagar.

2. HOD, Department of Psychiatry, Govt Medical College Srinagar', Kashmir (INDIA)

\section{CORRESPONDING AUTHOR}

Dr. Ab Majid Gania,

Consultant, Department of psychiatry,

SKIMS Medical College \& hospital Bemina, Srinagar.

E-mail: maajid72@gmail.com

Ph: 00919419071771

\begin{abstract}
Dually diagnosed patients pose a unique challenge to the psychiatrists during evaluation and management. Presence of comorbidity in substance using patients is a rule rather than exception. Working on these lines an outpatient based study was carried out in a tertiary care hospital, Srinagar, on 561 substance using patients, to work out the prevalence and patterns of comorbid BPAD. The subjects were assessed using MINI plus. Of these, $62.56 \%$ $(\mathrm{n}=351)$ had comorbidity, with BPAD being comorbid in $23.64 \%(\mathrm{n}=83)$. Most of the patients were in the age group of $15-26$ years $(39.75 \%)$. Majority were males $(63.85 \%)$ and unmarried (49.39\%). Most of the patients belonged to the middle class (78.32\%). Educated patients $(89.16 \%)$ outnumbered illiterates $(10.89 \%)$. Such high rates of comorbidity suggests functional relation between these two disorders and further discourse is warranted.
\end{abstract}

KEYWORDS: Substance use, comorbidity, BPAD.

INTRODUCTION: Interest in the study of co-occurrence between mood, anxiety disorders and substance use disorders has grown tremendously in past decade and a half. It has become clear that co-occurrence of these disorders is common and has definite impact on treatment of dually diagnosed patients. After DSM III-R (APA 1987) allowed clinicians to give multiple diagnoses when different syndromes occur together in one episode of illness, the issue of co morbidity has assumed a central stage in psychiatric records ${ }^{1}$.

The present study was undertaken to assess the prevalence of Bipolar affective disorder in substance use disorder patients and examined the temporal relationship between the two psychiatric disorders.

MATERIAL AND METHODS: Patients registered in the out-patient department of psychiatric diseases hospital, Srinagar were the source of the study. A semi-structured interview was used to record sociodemographic variables and history of drug use in patients.

Total of 561 substance use disorder patients diagnosed with the help of DSM-IV based MINI Plus were screened for a comorbid diagnosis of MINI Plus ${ }^{8}$ out of these 561, 351 patients had an associated psychiatric disorder. Among these dually diagnosed patients, 83 patients had BPAD as a co morbid diagnosis. The relative onset of concurrent disorders was rated on the basis of historical report during assessment. Patients with positive family history and co-morbid medical illness were excluded from study. 
RESULTS: Total of 561 substance use disorder patients were included in the study, out of which $62.56 \%(n=351)$ patients had an associated psychiatric disorder. Concurrent BPAD as dual diagnosis was present in $23.64 \%(\mathrm{n}=83)$ patients.

The age of cases ranged from 19-55 years with mean age 27.17 years +- S.D +- 5.23. The maximum number of patients $39.75 \%(n=33)$ belonged to $19-26$ age group followed by $30.12 \%$ $(n=25)$ 27-34 years of age group. This study was dominated by male sex as there were $63.85 \%$ $(n=53)$ males and 36.14\% $(n=30)$ females. Most of the cases were unmarried $49.39 \%(n=41)$ followed by married $39.75 \%(n=33)$ and $10.83 \%(n=)$ were divorcees or widowers. The middle class constituted most of our patient population i,e $78.32 \% \quad(n=65)$. Graduates and postgraduates constituted $48.84 \%(n=41)$ followed by matriculates $39.75 \%(n=33)$ and illiterates constituted only $10.84 \%(n=9)$ of our dually diagnosed Substance Use Disorder and BPAD patients. 50.60\% ( $\mathrm{n}=42)$ were government employees followed by $39.75 \%(\mathrm{n}=33)$ Laborers/ unemployed and 9.63\% (n=8) were students. 28 (33.73\%) patients had exclusively maniac episode/s, 37 (44.57\%) patients had an episode/s of mania and Depression, 13 (15.66\%) patients had a hypomania episode/s and a depressive episode/s and 5 (6.02\%) patients had mixed episode/s. Rest of the variables are depicted in table below.

Sample characteristics of substance use disorder patients with BPAD as comorbid diagnosis

\begin{tabular}{|c|c|c|c|c|c|c|c|c|}
\hline & \multicolumn{2}{|c|}{ Age in years } & \multicolumn{3}{|c|}{ Gender } & & \multicolumn{2}{|c|}{ Residential status } \\
\hline & Pts. & \%age & & Pts . & \%age & & Pts . & \%age \\
\hline $19-26$ & 33 & 39.75 & & & & & & \\
\hline $27-34$ & 25 & 30.12 & Male & 53 & 63.85 & Rural & 61 & 73.49 \\
\hline $35-42$ & 13 & 15.66 & & & & & & \\
\hline $43-50$ & 4 & 4.80 & Female & 30 & 36.14 & Urban & 22 & 26.50 \\
\hline \multirow[t]{3}{*}{$>50$} & 8 & $9.6 \%$ & & & & & & \\
\hline & \multicolumn{2}{|c|}{ Marital status } & \multicolumn{3}{|c|}{ Socioeconomic status } & & \multicolumn{2}{|c|}{ Occupation } \\
\hline & Pts. & \%age & & Pts & \%age & & Pts . & \%age \\
\hline Married & 33 & 39.75 & UC & 13 & 15.66 & Employed & 42 & 50.60 \\
\hline Unmarried & 41 & 49.39 & MC & 65 & 78.30 & Unemployed & 33 & 39.75 \\
\hline \multirow[t]{3}{*}{ Divorcee } & 5 & 6.02 & LC & 5 & 6.02 & Students & 08 & 9.63 \\
\hline & \multicolumn{2}{|c|}{ Education } & & & & & \multicolumn{2}{|c|}{ Drugs used } \\
\hline & Pts. & \%age & & & & & Pts . & \%age \\
\hline Illetrate & 9 & 10.84 & & & & Bzp & 21 & 25.30 \\
\hline Matric & 33 & 39.75 & & & & Bzp $+0 p+$ Can & 33 & 39.75 \\
\hline Graduates & 29 & 34.39 & & & & Opioids & 25 & 30.12 \\
\hline $\begin{array}{l}\text { Post } \\
\text { graduates }\end{array}$ & 12 & 14.45 & & & & alcohol & 4 & 4.8 \\
\hline
\end{tabular}

DISCUSSION: The present study assessed the prevalence of bipolar affective disorder in substance use disorder patients, their sociodemographic variables and relationship between the two disorders. $62.56 \%(\mathrm{n}=351)$ patients had an associated psychiatric disorder and concurrent BPAD as dual diagnosis was present in $23.64 \%(n=83)$ patients. 
Co-occurrence of bipolar affective disorders in patients with substance use disorders has been documented by studies like Feinman and Dunner et al (1996) ${ }^{2}$ which showed alcohol abuse and dependence was present in 50\% of BPAD I and $60 \%$ of BPAD II diagnosis. Reiger et al (1990) ${ }^{3}$ also observed in their studies that bipolar I had substance use prevalence of $60.7 \%$. In fact Bipolar I is the third commonest diagnosis after antisocial disorder and schizophrenia in patients with alcohol related problems ${ }^{4}$. Studies which are in agreement with our findings include Kishore et al (1994) ${ }^{5}$ and Ghanizadeh et al (2000) ${ }^{6}$. Ross et al (1988) ${ }^{7}$ in their study showed that $34 \%$ had life time bipolar affective disorder in patients with alcohol and other drug problems. The significant finding was lower percentage of BPAD patients in our substance using population. The reason for lower percentage of bipolar affective disorder patients in our study as compared to other studies from rest of the world could be alcohol being less commonly used substance in our valley, as it's not a socially approved beverage in this part of the world8. In addition there are many studies which show strong relationship between co-occurrence of alcohol use and $\mathrm{BPAD}^{2,3,7}$. This further establishes the fact that there is a strong co-relation between alcohol use and BPAD.

Most of these studies and our study confirm that co morbidity between substance use disorders and Bipolar affective disorder is common and symptoms of dually diagnosed patients tend to be more severe and refractory to treatment. Our study also revealed that most of our dually diagnosed patients were young males and females from middle class and most of these dually diagnosed patients used combination of drugs.

\section{REFRENCES:}

1. American psychiatric association (1987): diagnostic and stastical manual of mental disorders. (3 ed. Revised)

2. Feinman JA, Dunner DL Effect of alcohol and substance abuse on the course of BPAD.

3. Journal of affective disorders 1996; $37 ; 43-49$

4. Darrel A. Regier, Mary E. Farmer, D S, Rae Comorbidity of mental disorders with alcohol and other drug abuse JAMA 1990; Nov 264; 2511-2518 Kaplan and Saddocks Text book of Psychiatry 9th Edition

5. Pankaj Kishore, Narotam Lal, J. K Trivedi A Study of comorbidity in psychoactive substance dependence patients Indian Journal of Psychiatry 1996;36(3); 133-137

6. Ghanizadeh A, Ashkani H, Manny I Comorbidity of psychiatric disorders in Iranian treatment seeking Opioid addicts. Iranian Journal of Medical Sciences 2000；25 (1\&2); 25-30

7. Hellen E Ross, Fedrick B Glaser and Teresa Germanson The prevalence of psychiatric disorders in patients with alcohol and other drug problems. Archives of general Psychiatry 1988; $\quad 45 ; \quad 1023-1031$

8. MargoobMA,Ab. Majid,Arshid Hussain changing Sociodemographic pattern of substance abuse in Kashmir valley. JK Practitioner Jan Mar 2004 vol.II No. 1 14-16 